\title{
Microenxertia e sua caracterização morfológica em Araucaria angustifolia
}

\author{
Micrografting morphological characterization in Araucaria angustifolia
}

\author{
Justina Inês Anselmini ${ }^{I}$ Flávio Zanette ${ }^{\text {II }}$
}

\section{RESUMO}

\begin{abstract}
O objetivo deste trabalho foi determinar a melhor técnica para microenxertia em Araucaria angustifolia. Para isto, foram realizadas auto-enxertias em plantas germinadas in vitro, com 2, 6 e 12 meses de idade. Foram testados dois locais de enxertia no porta-enxerto: caule e hipocótilo, e dois tipos de enxertia: garfagem de topo com e sem fenda. A maior porcentagem de microenxertos com fenda aberta ocorreu nas microenxertias realizadas no hipocótilo. As maiores porcentagens de microenxertos sobreviventes foram obtidas nas microenxertias realizadas no caule, e o tipo de enxertia mais eficiente foi a garfagem de topo sem fenda. A presença de calo aparente foi resultado da interação dos três fatores testados, com maior presença de calo nas enxertias realizadas no hipocótilo. O crescimento dos microenxertos indicou o restabelecimento das conexões vasculares. O maior crescimento dos microenxertos foi obtido nas enxertias realizadas no caule em porta-enxertos de 6 meses com a garfagem de topo. As metodologias testadas permitem concluir que o processo de microenxertia em Araucaria angustifolia é eficiente e factível, podendo ser utilizado para a produção de mudas microenxertadas.
\end{abstract}

Palavras-chave: pinheiro-do-paraná, biotecnologia, micropropagação, cultura de tecidos.

\section{ABSTRACT}

The objeticve of this research was to determine a more efficient way of micrografting in vitro Araucaria angustifolia plants. Autografting was performed onto 2, 6- and 12- month- old in vitro germinated plants. Two different graft types (saddle with or without slit) were perfomed on two different plant parts (stem or hypocotyl). Higher percentage of open slit micrografts was observed when micrografting was performed onto hypocotyls. Higher percentage of surviving micrografts was obtained when micrografting was perfomed on stem; the saddle without slit technique was the most efficient. Callus formation resulted from the combination of the three tested factors. However, more visible calluses were present in micrograftings perfomed on hypocotyls. Growth of the micrograftings was an indication of vascular connection recovering. Better growth was observed whem micrograftings were slit saddled onto 6-month-old stems. The methodology tested herein allowed us to conclude that the micrografting process is effective and efficient and may be used for production of Araucaria angustifolia micrografted plants.

Key words: parana-pine, biotechnology, micropropagation, tissue culture.

\section{INTRODUÇÃO}

Dentre as várias técnicas de propagação vegetativa in vitro e ex vitro, a estaquia (IRITANI, 1981), a enxertia (IRITANI, 1997) e técnicas de cultura de tecidos (ZANETTE et al., 1987; SANTOS et al., 2002) foram as mais utilizadas para a Araucaria angustifolia, na tentativa de desenvolver um protocolo eficiente para a produção de mudas da espécie.

Apesar de a enxertia ser considerada uma técnica de propagação vegetativa viável para a araucária, alguns fatores têm influenciado negativamente o seu êxito, como o plagiotropismo característico da espécie e a diferença entre os diâmetros do porta-enxerto e do enxerto, a sensibilidade das gemas às altas temperaturas e a baixa umidade relativa, e o grau de lignificação das mudas (IRITANI, 1997).

Neste sentido, a microenxertia é utilizada para superar dificuldades apresentadas em frutíferas e

\footnotetext{
'Programa de Pós-graduação em Agronomia, Produção Vegetal, Universidade Federal do Paraná (UFPR). Rua dos Funcionários 1540, CP 19061, Juvevê, 80035-050, Curitiba, PR, Brasil. E-mail: justinaines@pop.com.br. Autor para correspondência.

IIDepartamento de Fitotecnia e Fitossanitarismo, UFPR, Curitiba, PR, Brasil.
} 
essências florestais na regeneração de ápices caulinares (PAZ \& PASQUAL, 1998). Essa técnica é também utilizada para a obtenção de plantas livres de viroses (PAZ \& PASQUAL, 1998; PASQUAL, 2001), possibilitando a produção de matrizes de fruteiras com alta qualidade fitossanitária e com características adultas (PAZ \& PASQUAL, 1998). É também uma técnica promissora para detecção precoce de reação de incompatibilidade entre as duas partes enxertadas (HARTMANN et al., 1997).

A enxertia é a união de tecidos de um mesmo indivíduo (autoenxertia), ou de indivíduos diferentes pertencentes à mesma espécie (homoenxertia) ou não (heteroenxertia), e a primeira condição para que esta união seja satisfatória é a compatibilidade entre as partes. Os primeiros sintomas de incompatibilidade entre o enxerto e o porta-enxerto são a fraca união das partes, a murcha e senescência das folhas, o colapso dos tubos crivados e a conseqüente morte do enxerto (CARVALHO, 2002).

Outras causas do não-pegamento de um enxerto estão na época do ano e na técnica inadequadas. A perfeita união das camadas cambiais das duas partes enxertadas é uma condição fundamental para o êxito da enxertia, por isso a importância de determinar a técnica mais apropriada para a enxertia (CARVALHO, 2002).

O objetivo deste trabalho foi estudar uma boa técnica para microenxertia em Araucaria angustifolia, para possibilitar a clonagem de material adulto com genótipos superiores, visando à formação de pomares clonais para produção de sementes de qualidade ou para reflorestamentos uniformes.

\section{MATERIAL E MÉTODOS}

O presente trabalho foi realizado no Laboratório de Micropropagação de Plantas do Departamento de Fitotecnia e Fitossanitarismo do Setor de Ciências Agrárias da Universidade Federal do Paraná, nos anos de 2005 e 2006. Os porta-enxertos de Araucaria angustifolia utilizados nos experimentos foram obtidos da germinação in vitro de embriões, e mantidos por 2, 6 e 12 meses nesta condição.

As sementes utilizadas foram coletadas de uma planta adulta com mais de 20 anos, plantada e situada no setor de Ciências Agrárias da UFPR. A assepsia das sementes foi realizada com a imersão dos pinhões, sem o tegumento, por cinco minutos em etanol (70\%) e hipoclorito de sódio $(6 \%)$ por 40 minutos, seguida de três lavagens em água destilada e autoclavada em câmara de fluxo laminar. O endosperma foi retirado em câmara de fluxo laminar com auxílio de pinças e bisturi e os embriões foram lavados em água destilada e autoclavada e secados sobre papel absorvente autoclavado. Em seguida, os embriões foram inoculados individualmente em tubos de ensaio, contendo $10 \mathrm{~mL}$ de meio WPM (LLOYD \& McCOWN, $1980)$ acrescido de sacarose $\left(20 \mathrm{~g} \mathrm{~L}^{-1}\right)$, ágar $\left(6 \mathrm{~g} \mathrm{~L}^{-1}\right)$ e carvão ativado $\left(1 \mathrm{~g} \mathrm{~L}^{-1}\right)$. Os tubos de ensaio foram transferidos para sala de crescimento sob regime de 16 horas de fotoperíodo, em temperatura controlada de $25 \pm 1^{\circ} \mathrm{C}$, e radiação luminosa de $24,3 \mathrm{mmol}^{-2} \mathrm{~s}^{-1}$, fornecida por lâmpadas fluorescentes de tipo "luz branca".

Os explantes utilizados como enxertos foram obtidos dos ápices das próprias plantas germinadas in vitro. A parte apical das plantas foi retirada e o tamanho do microenxerto foi padronizado em $5 \mathrm{~mm}$. Portanto, os porta-enxertos foram microenxertados com seus próprios ápices (auto-enxertia). A microenxertia foi realizada através de um corte em fenda simples (garfagem de topo em fenda cheia) e um corte horizontal (garfagem de topo sem fenda). Os cortes foram feitos $5 \mathrm{~mm}$ abaixo ou acima da região de inserção hipocótilocaule.

Os microenxertos foram inoculados em tubos de ensaio com $15 \mathrm{~mL}$ de meio de cultura WPM contendo sacarose $\left(20 \mathrm{~g} \mathrm{~L}^{-1}\right)$, ágar $\left(6 \mathrm{~g} \mathrm{~L}^{-1}\right)$ e carvão ativado $\left(1 \mathrm{~g} \mathrm{~L}^{-1}\right)$ e mantidos em sala de crescimento nas condições de cultivo descritas anteriormente para a obtenção dos porta-enxertos.

Após 60 dias de cultivo in vitro, foram realizadas as seguintes avaliações: porcentagem de microenxertos com abertura da fenda, porcentagem de microenxertos mortos, porcentagem de microenxertos vivos com presença de calo aparente. Após 90 dias de cultura, foi avaliado o crescimento dos microenxertos.

O delineamento utilizado foi inteiramente casualizado com três repetições e cinco microenxertias por repetição. Os tratamentos foram arranjados num fatorial de $3 \mathrm{X} 2 \mathrm{X} 2$, sendo três idades de porta-enxertos (dois, seis e 12 meses), dois locais de enxerto: caule e hipocótilo, e dois tipos de enxertia: garfagem de topo (fenda cheia) e garfagem de topo sem fenda. Foi realizada a análise de variância e comparação de médias pelo Teste de Tukey, em nível de 5\% de probabilidade de erro.

Para a caracterização morfológica dos microenxertos, foi realizado um outro experimento na mesma época, onde foram utilizados os mesmos tratamentos: dois locais de enxerto: caule e hipocótilo, e dois tipos de enxertia: garfagem de topo (fenda cheia) e garfagem de topo sem fenda em plantas germinadas in vitro, com 12 meses de idade. Para cada tratamento, foram feitas nove microenxertias e, a cada 30 dias, foram retiradas três plantas microenxertadas, num total de três coletas.

As amostras coletadas foram fixadas imediatamente em FAA (solução de formaldeído, ácido acético glacial e etanol (50\%), nas proporções de 5:5:90),

Ciência Rural, v.38, n.4, jul, 2008. 
segundo JOHANSEN (1940). Após 48 horas na solução de FAA, as amostras foram colocadas em etanol $70 \%$ até o momento da infiltração, quando foram desidratadas em etanol e processadas segundo as técnicas de FEDER \& O’BRIEN (1968) para inclusão em meta-acrilatoglicol, segundo as recomendações do fabricante (JB4 - Poliscience $\left.{ }^{\hat{a}}\right)$. As secções seriadas, com $5 \mu \mathrm{m}$ de espessura, foram obtidas em micrótomo de rotação, distendidas sobre lâminas histológicas e secadas em temperatura ambiente. As lâminas foram coradas em solução aquosa de azul de toluidina $(0,5 \%)$. A montagem das lâminas foi feita com lamínulas e resina sintética $\left(\right.$ Entelan $\left.^{\grave{ }}\right)$.

\section{RESULTADO E DISCUSSÃO}

Nos tratamentos com garfagem de topo em fenda cheia, as médias obtidas para os microenxertos com fenda aberta mostraram uma diferença estatisticamente significativa entre o hipocótilo e o caule, com $4,44 \%$ de microenxertos com fenda aberta no caule e $37,8 \%$ no hipocótilo dos porta-enxertos. A presença de fenda aberta está diretamente relacionada com a não-sobrevivência dos microenxertos, pois impedem o contato entre as duas partes e o restabelecimento da conexão dos vasos condutores (Figura 1A). A inviabilidade dos enxertos também pode ocorrer pelo deslocamento do enxerto sobre o portaenxerto, com o desemparelhamento dos tecidos vasculares entre as duas partes (NUNES et al., 2005).

O hipocótilo foi testado como órgão para microenxertia por apresentar um diâmetro uniforme $\mathrm{e}$ maior que os caules dos porta-enxertos de Araucaria angustifolia testados. O hipocótilo forma, junto com a radícula, a região adaxial do embrião da araucária, que se caracteriza como uma região cilíndrica e de diâmetro uniforme, onde estão inseridos os dois cotilédones (HERTEL, 1980).

A maior porcentagem de microenxertos com fenda aberta no hipocótilo pode estar relacionada à sua estrutura, sendo que alguns autores não consideram que o hipocótilo possuia estrutura radicular, caulinar ou de órgão composto parcialmente de raiz e caule. Para SOUZA \& OLIVEIRA (2004), foi adotado na descrição do hipocótilo de Tabebuia avellanedae e T. chrysotricha o conceito de região de transição. Isto também é aceito por anatomistas, como ESAU (1985), que ressalta que a região do hipocótilo representa uma conexão, sendo um órgão intermediário entre a raiz e o caule.

A porcentagem de microenxertos sobreviventes mostrou uma interação significativa entre os fatores: idade dos porta-enxertos e tipo de enxertia, e interação entre local do microenxerto e tipo de enxertia (Tabela 1). Para o fator idade dos porta- enxertos, nas plantas com 6 e 12 meses, não houve diferença significativa entre a porcentagem de microenxertos sobreviventes para os dois tipos de enxertia, mas para os porta-enxertos com dois meses a garfagem de topo sem fenda foi mais eficiente, não apresentando microenxertos mortos (Tabela 1). Em relação ao tipo de enxertia, na garfagem de topo sem fenda, os resultados foram semelhantes estatisticamente; já na garfagem de topo em fenda cheia, os porta-enxertos com 12 meses apresentaram maior porcentagem de microenxertos sobreviventes que os porta-enxertos com dois e seis meses.

O local do microenxerto causou diferenças significativas quando realizadas no hipocótilo, com a garfagem de topo sem fenda sendo mais eficiente quanto à sobrevivência dos microenxertos (Tabela 1). A garfagem de topo sem fenda não apresentou diferenças entre o caule e o hipocótilo; entretanto, para a garfagem de topo em fenda cheia, aquelas realizadas no caule apresentaram maior média de microenxertos sobreviventes em relação àquelas realizadas no hipocótilo.

As porcentagens de microenxertos sobreviventes foram boas quando comparadas com outros dados obtidos em trabalhos com macieira, nos quais NUNES et al. (2005) obtiveram uma porcentagem de sobrevivência de até 93\% para a cultivar "Gala" microenxertada sobre "M9" e de 86\% para "Gala" microenxertada sobre "Marubakaido". Em citrus, a microenxertia com brotações regeneradas in vitro apresenta $100 \%$ de pegamento (SILVA et al., 2005).

A sobrevivência dos microenxertos comprova a capacidade organogenética dos tecidos para a regeneração e indica que esta técnica é viável e que pode ser utilizada na produção de mudas microenxertadas para a espécie, abrindo perspectivas para a produção de mudas de alta qualidade a partir de microenxertias com ápices de plantas adultas.

A porcentagem de microenxertos vivos com calo aparente na região da enxertia (Figura 1B), apresentou uma interação significativa entre os três fatores, idade dos porta-enxertos, local e tipo da enxertia (Tabela 2). Para os porta-enxertos com dois meses, quando a microenxertia foi realizada no caule, a porcentagem de calo aparente foi maior para a garfagem de topo em fenda cheia. O inverso ocorreu para as microenxertias realizadas no hipocótilo, com $100 \%$ dos microenxertos com calo aparente na garfagem de topo sem fenda. Quanto ao tipo de enxertia, na garfagem de topo em fenda cheia, não houve diferenças significativas entre o enxerto no caule e no hipocótilo; já para a garfagem de topo sem fenda, o caule apresentou uma média de microenxertos com calo inferior em relação ao hipocótilo. 

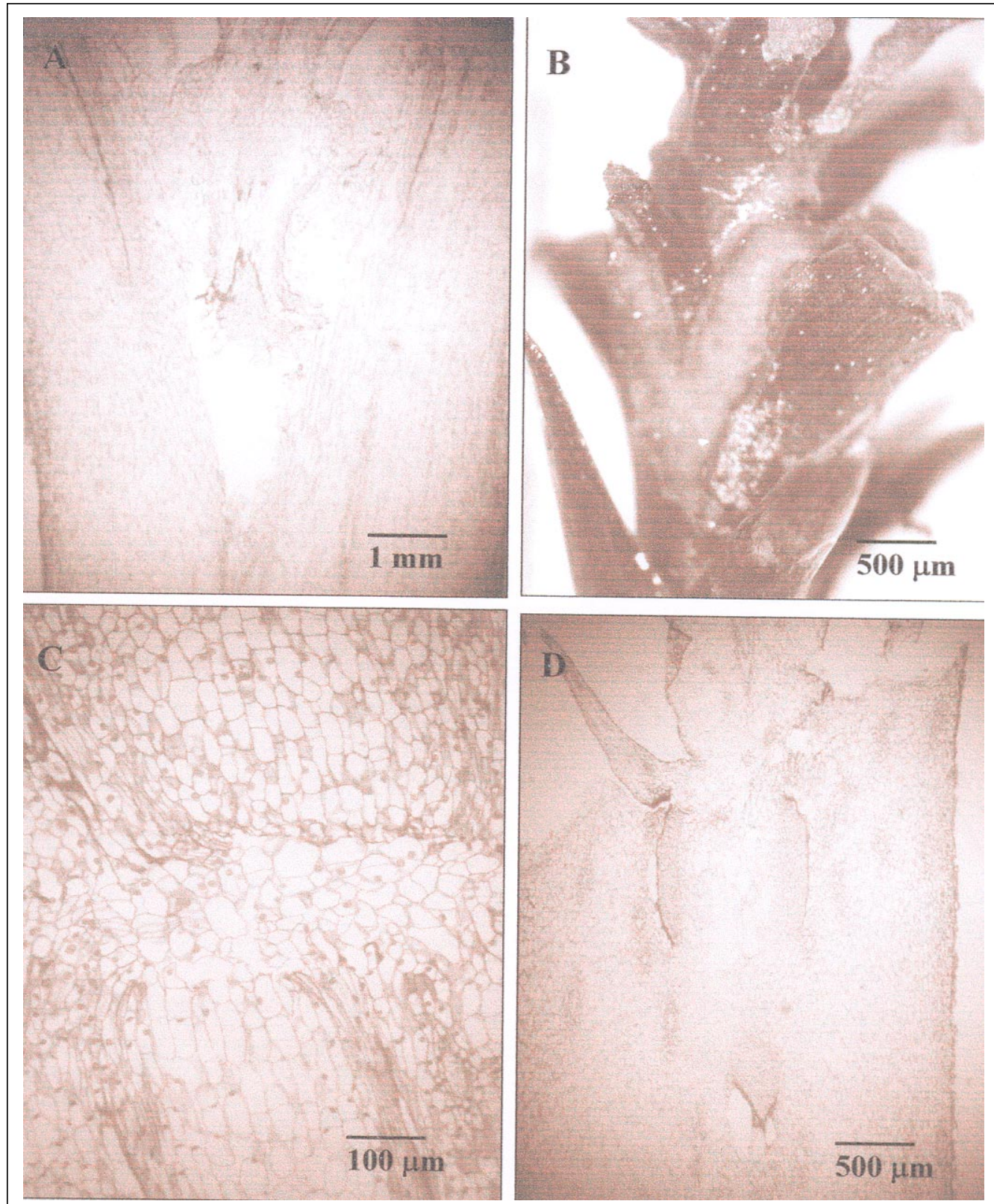

Figura 1 - Microenxertias em Araucaria angustifolia; A) Garfagem de topo no hipocótilo, a fenda aberta dificulta a conexão entre os tecidos do microenxerto e do porta-enxerto, 30 dias após a microenxertia; B) Garfagem do topo (fenda cheia) no caule, presença de calo indicando a soldadura entre as partes enxertadas, 60 dias após a microenxertia; C) interface microenxerto e porta-enxerto, garfagem de topo sem fenda, com desenvolvimento de tecido meristemático caracterizando o processo de soldura entre as partes, 30 dias após a microenxertia; D) garfagem de topo (fenda cheia) no hipocótilo, com a proliferação do tecido cambial do microenxerto, 90 dias após a microenxertia.

Nos porta-enxertos com seis meses de idade, não houve diferença entre os tipos de enxertias realizadas no caule; mas, para as realizadas no hipocótilo, a garfagem de topo em fenda cheia apresentou uma média significativamente superior de microenxertos com calo que a garfagem de topo sem fenda (Tabela 2).
Nos porta-enxertos com 12 meses, não houve diferença entre os dois tipos de enxertia quando realizadas no hipocótilo; no entanto, no caule, a enxertia por garfagem de topo sem fenda apresentou menor porcentagem de calo. Para o tipo de enxertia, apenas a garfagem de topo sem fenda apresentou diferenças

Ciência Rural, v.38, n.4, jul, 2008. 
Tabela 1 - Porcentagem de microenxertos sobreviventes em Araucaria angustifolia.

\begin{tabular}{lcr}
\hline Idade do porta-enxerto (meses) & Garfagem de topo em fenda cheia (\%) & Garfagem de topo sem fenda (\%) \\
\hline 2 & $76,7 \mathrm{~B} \mathrm{~b}$ & $100,0 \mathrm{~A} \mathrm{a}$ \\
6 & $73,4 \mathrm{~A} \mathrm{~b}$ & $86,7 \mathrm{~A} \mathrm{a}$ \\
12 & $96,7 \mathrm{~A} \mathrm{a}$ & $86,7 \mathrm{~A} \mathrm{a}$ \\
Local do microenxerto & Garfagem de topo em fenda cheia (\%) & Garfagem de topo sem fenda (\%) \\
Caule & $93,4 \mathrm{~A}$ a & 88,9 A a \\
Hipocótilo & $71,1 \mathrm{~B} \mathrm{~b}$ & $93,3 \mathrm{~A}$ a \\
CV $(\%)$ & & 79 \\
\hline
\end{tabular}

Médias não seguidas de mesma letra maiúscula na linha e mesma letra minúscula na coluna diferem significativamente pelo Teste de Tukey, em nível de 5\% de probabilidade de erro.

significativas, com maior porcentagem de calo nos microenxertos realizados no hipocótilo.

Os dados permitem visualizar que, de um modo geral, a porcentagem de calo aparente formado foi maior nas microenxertias realizadas no hipocótilo, indicando uma diferença na sua estrutura, que, conforme PILATI \& SOUZA (2006), mesmo em fase mais adiantada de crescimento secundário uma medula parenquimática é mantida.

A formação de calo indica a proliferação celular, com potencialidade para gerar novos elementos vasculares, que possibilitam a conexão vascular entre o enxerto e o porta-enxerto. NUNES et al. (2005) também constataram a formação de calo em microenxertias realizadas com variedades de porta-enxerto e copa de macieira.

Após a microenxertia, ocorreu a formação de camadas de células parenquimáticas que preencheram o local do microenxerto (Figura 1C) e a diferenciação de algumas destas células em novas células cambiais, que restabeleceram a conexão cambial entre os tecidos (Figura 1D). Estas observações estão de acordo com as de ABREU \& PEDROTTI (2003), que observaram em macieira o restabelecimento das conexões cambiais e o conseqüente crescimento do enxerto 30 dias após a microenxertia. ABREU et al. (2003) observaram na mesma espécie, 30 dias após a microenxertia, células meristemáticas cambiais na copa próximas à interface do enxerto, penetrando no portaenxerto. Algumas destas células ainda eram indiferenciadas e outras já se caracterizavam como parenquimáticas ou vasculares jovens.

$\mathrm{O}$ crescimento do enxerto indica o sucesso da enxertia. A primeira evidência da proliferação celular é o início do crescimento do enxerto, pois indica o restabelecimento das conexões vasculares entre os tecidos (NUNES et al., 2005). De acordo com ABREU \& PEDROTTI (2003), para viabilizar a microenxertia, é necessário que as células da base do microenxerto entrem novamente em divisão e se desdiferenciem induzindo novas competências, como a de se diferenciar para formar novos tecidos estruturais e condutores.

Após 90 dias da microenxertia, a diferença entre os tamanhos dos microenxertos foi significativo com relação à idade dos porta-enxertos, ao local do microenxerto e ao tipo de enxertia (Tabela 3 ).

Tabela 2 - Porcentagem dos microenxertos com calo aparente na região da enxertia, em Araucaria angustifolia.

\begin{tabular}{|c|c|c|c|}
\hline \multirow{2}{*}{ Idade do porta-enxerto (meses) } & \multirow{2}{*}{ Local do microenxerto } & \multicolumn{2}{|c|}{------------------------------------Tipo de enxertia------------------------------- } \\
\hline & & Garfagem de topo em fenda cheia & Garfagem de topo sem fenda \\
\hline \multirow{2}{*}{2} & caule & $46,6 \mathrm{~A} \mathrm{a}$ & $6,6 \mathrm{~B} \mathrm{~b}$ \\
\hline & hipocótilo & $53,3 \mathrm{~B} \mathrm{a}$ & $100,0 \mathrm{~A} \mathrm{a}$ \\
\hline \multirow{2}{*}{6} & caule & $0,0 \mathrm{~A} \mathrm{~b}$ & $13,3 \mathrm{~A} \mathrm{a}$ \\
\hline & hipocótilo & $40,0 \mathrm{~A} \mathrm{a}$ & $6,6 \mathrm{~B} \mathrm{a}$ \\
\hline \multirow{2}{*}{12} & caule & $40,0 \mathrm{~A} \mathrm{a}$ & $6,6 \mathrm{~B} \mathrm{~b}$ \\
\hline & & & \\
\hline $\mathrm{CV}(\%)$ & & \multicolumn{2}{|c|}{37,5} \\
\hline
\end{tabular}

Médias não seguidas de mesma letra maiúscula na linha e mesma letra minúscula na coluna diferem significativamente pelo Teste de Tukey, em nível de $5 \%$ de probabilidade de erro. 
Tabela 3 - Tamanho médio dos microenxertos após 90 dias da microenxertia, em Araucaria angustifolia.

\begin{tabular}{lc}
\hline Idade do porta-enxerto (meses) & Crescimento dos microenxertos (cm) \\
\hline 2 & $0,47 \mathrm{c}$ \\
6 & $0,92 \mathrm{a}$ \\
12 & $0,60 \mathrm{~b}$ \\
Local do microenxerto & Crescimento dos microenxertos (cm) \\
Caule & $0,81 \mathrm{a}$ \\
Hipocótilo & $0,51 \mathrm{~b}$ \\
Tipo de enxertia & Crescimento dos microenxertos (cm) \\
Garfagem de topo em fenda cheia & $0,87 \mathrm{a}$ \\
Garfagem de topo sem fenda & $0,45 \mathrm{~b}$ \\
C V (\%) & 60,8 \\
\hline
\end{tabular}

Médias não seguidas de mesma letra maiúscula na linha e mesma letra minúscula na coluna diferem significativamente pelo Teste de Tukey, em nível de $5 \%$ de probabilidade de erro.

Os porta-enxertos com seis meses de idade apresentaram o maior crescimento dos microenxertos, e o menor foi observado em porta-enxertos com dois meses. Isso confirma as observações de PAZ \& PASQUAL (1998), que mostraram que a idade do microporta-enxerto é um fator que influencia o sucesso da enxertia.

Quanto ao local da enxertia, o maior crescimento foi obtido para as microenxertias realizadas no caule, o que provavelmente foi devido à maior semelhança entre os tecidos enxertados. A garfagem de topo em fenda cheia apresentou o maior crescimento dos microenxertos após 90 dias, sendo atribuída a este tipo de enxertia um maior contato entre as partes enxertadas, o que pode ter favorecido o restabelecimento precoce das conexões vasculares e o pegamento dos microenxertos.

\section{CONCLUSÃO}

As metodologias desenvolvidas permitem concluir que o processo de microenxertia em Araucaria angustifolia é eficiente e factível. Recomenda-se na propagação in vitro de A. angustifolia a enxertia de garfagem de topo sem fenda, realizada no caule de plantas com dois meses de germinação.

\section{REFERÊNCIAS}

ABREU, M.F. et al. Estudos histológicos preliminares da microenxertia de plantas micropropagadas de macieira. Revista Brasileira de Fruticultura, v.25, n.1, p.195-196, 2003.

ABREU, M.F.; PEDROTTI, E.L. Micropropagação de macieira. Revista Biotecnologia Ciência \& Desenvolvimento, n.31, p.100-108, 2003.
CARVALHO, R.I.N. Fisiologia de produção de espécies frutíferas. In: WACHOWICZ, C.M.; CARVALHO, R.I.N. Fisiologia vegetal: produção e pós-colheita. Curitiba: Champagnat, 2002. Cap.6, p.135-182.

ESAU, K. Anatomia vegetal. 3.ed. Barcelona: Omega, 1985. 780 p.

FEDER, N.; O'BRIEN, T.P. Plant microtechnique: some principles and new methods. American Journal of Botany, v.55, n.1, p.123-142, 1968.

HARTMANN, H.T. et al. Principles of tissue culture for micropropagation. In: ______ Plant propagation: principles and practices. 6.ed. New Jersey: Prentice Hall, 1997. p.549-589.

HERTEL, R.J.G. Interpretação morfológica da Araucaria angustifolia. 1980. 143f. Tese (Acesso à Classe de professor titular na área de Morfologia Vegetal) - Setor de Ciências Biológicas, Universidade Federal do Paraná.

IRITANI, C. Ação de reguladores de crescimento na propagação vegetativa por estaquia de Ilex paraguariensis Saint Hilare e Araucaria angustifolia (Bert.) O. Ktze. 1981. 163f. Dissertação (Mestrado em Ciências, Engenharia Florestal) - Setor de Ciências Agrárias, Universidade Federal do Paraná.

IRITANI, C. Aspectos múltiplos da cultura in vitro da Araucaria angustifolia (Bert) O. Ktze. 1997. 200f. Tese (Doutorado em Engenharia Florestal) - Setor de Ciências Agrárias, Universidade Federal do Paraná.

JOHANSEN, D.A. Plant microtechnique. New York: Mc Graw Hill Book, 1940. 523p.

LLOYD, G.; McCOWN, B. Commercially feasible micropropagation of mountain laurel, Kalmia latifolia by use of shoot-tip culture. Combined Proceedings International Plant Propagators Society, v.3, p.421-427, 1980.

NUNES, J.C.O. et al. Caracterização morfológica de microenxertia em macieira. Revista Brasileira de Fruticultura, v.27, n.1, p.80-83, 2005. 
PASQUAL, M. Introdução: fundamentos básicos. In: PASQUAL, M. Cultura de tecidos vegetais: tecnologias e aplicações. Lavras: UFLA/FAEPE, 2001. 97p.

PAZ, O.P.; PASQUAL, M. Microenxertia. In: TORRES, et al. Cultura de tecidos e transformação genética de plantas. Brasília: Embrapa-CNPH, 1998. V.1, p.147-160.

PILATI, R.; SOUZA, L.A. Morfoanatomia da plântula de Celtis iguanaea (Jacq.) Sarg. (Ulmaceae). Acta Scientiarum Biological Sciences, v.28, n.1, p.1-6, 2006.

SANTOS, A.L. et al. Somatic embryogenesis in Parana pine Araucaria angustifolia (Bert.) O. Ktze. Brazilian Archives of Biology and Technology, v.45, n.01, p.97-104, 2002.
SILVA, R.P. et al. Regeneração de plantas de laranja 'Pêra' via organogênese in vitro. Pesquisa Agropecuária Brasileira, v.40, n.12, p.1153-1159, 2005.

SOUZA, L.A.; OLIVEIRA, J.H.G. Morfologia e anatomia das plântulas de Tabebuia avellanedae Lor. Ex Griseb e T. chrysotricha (Mart. ex Dc.) Standl. (Bignoniaceae). Acta Scientiarum Biological Sciences, v.26, n.2, p.217-226, 2004.

ZANETTE, F. et al. Aspectos básicos da cultura in vitro de Araucaria angustifolia. I. Organização e desenvolvimento dos meristemas axilares. Revista do Setor de Ciências Agrárias, v.9, p.7-13, 1987. 